\title{
Plant regeneration of Anthurium andreanum cv Rubrun
}

\author{
Teresa E. Vargas \\ Laboratorio de Biotecnología Vegetal \\ Instituto de Biología Experimental, Facultad de Ciencias \\ Universidad Central de Venezuela \\ Caracas, Apartado 47114 Los Chaguaramos, \\ Venezuela \\ Tel: 582127510111 \\ Fax: 582127535897 \\ E-mail: jojoagon@hotmail.com
}

Alexander Mejías

Laboratorio de Biotecnología Vegetal

Instituto de Biología Experimental, Facultad de Ciencias

Universidad Central de Venezuela

Caracas, Apartado 47114 Los Chaguaramos, Venezuela

Tel: 582127510111

Fax: 582127535897

E-mail: alexandermejias@hotmail.com

\section{Maira Oropeza*}

Laboratorio de Biotecnología Vegetal

Instituto de Biología Experimental, Facultad de Ciencias

Universidad Central de Venezuela

Caracas, Apartado 47114 Los Chaguaramos,

Venezuela

Tel: 582127510111

Fax: 582127535897

E-mail: moropeza@strix.ciens.ucv.ve

\section{Eva de García}

Laboratorio de Biotecnología Vegetal Instituto de Biología Experimental, Facultad de Ciencias

Universidad Central de Venezuela

Caracas, Apartado 47114 Los Chaguaramos,

Venezuela

Tel: 582127510111

Fax: 582127535897

E-mail: egarcia@reacciun.ve

Financial support: This work was supported by the Council for Scientific and Humanistic Development (CDCH), Central University of Venezuela grant PI 03334393-2002 to Maira Oropeza.

Keywords: Callus, micropropagation, organogenesis.

Abbreviations: BA: $\mathrm{N}^{6}$-benzyladenine;

NAA: a-naphthaleneacetic acid.

To establish an efficient regeneration system for Anthurium andreanum cv Rubrun, seeds from plant spadixes were germinated on a medium supplemented with $2.2 \mu$ M BA. After 2 weeks, $74 \%$ of the seeds germinated and four weeks later, micro-cuttings from these plantlets were subcultured on a medium containing $4.4 \mu \mathrm{M}$ BA and $0.05 \mu \mathrm{M}$ NAA. On average, 3.6 shoots per explant were obtained. Four weeks old in vitro plants from germinated seeds and the plantlets obtained from micro-cuttings, showed callus proliferation at the stem base. These tissues were subcultured on a medium supplemented with $8.9 \mu \mathrm{M} \mathrm{BA}$ and $2.7 \mu \mathrm{M}$ NAA. After 6 weeks of culture, about 43.8 plantlets per square $\mathrm{cm}$ of callus were obtained. Anatomical studies showed the organogenic nature of these calli. Anthurium andreanum plants regenerated by organogenesis were transferred to pots and a rate of $80 \%$ of plant acclimatization was obtained.

The Anthurium genus comprises about 1500 tropical

*Corresponding author 


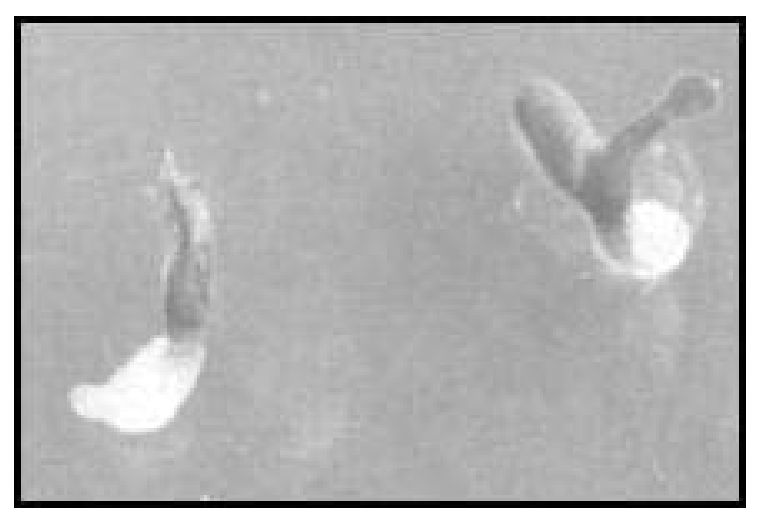

Figure 1. Seed germination of $A$. andreanum, two weeks after inoculation.

species which are important ornamental plants and are normally propagated by seed (Dufour and Guerin, 2003). Vegetative propagation methods applied to these plants have not shown good results and tissue culture techniques appear as an alternative to increase the production (Pierik et al. 1974, Chen et al. 1997). Plant regeneration of Anthurium andreanum has been achieved through adventitious shoots formation from callus (Pierik et al. 1974; Pierik and Steegmans, 1976) and direct shoot regeneration from lamina explants (Martin et al. 2003). Teng (1997) established the fact that in liquid or raft cultures most adventitious Anthurium shoots regenerated singly or in loose aggregates, which is an advantage over solid cultures. Geier (1986) concluded that plant age and plant genotype influence plant regeneration of Anthurium andreanum, and analyzed the influence of $\mathrm{NH}_{4} \mathrm{NO}_{3}$ on callus and shoots formation from young leaf tissues. Kuehnle and Sugii (1991) established a regeneration system from leaves and petioles of Anthurium Hawaiian cultivars through callus tissue cultures, and Kunisaki (1980) established the micropropagation of Anthurium from axillary buds. Chen et al. (1997) regenerated Anthurium andreanum plants from roots explants.

Reliable proliferation of callus and subsequent plant regeneration are important for massive plant propagation, studies on genetic transformation and development of transgenic plants with new trails. The improvement of the micropropagation system for this species could be important for its commercial applicability. This paper describes the preliminary results for the establishment of an alternative method for regeneration of Anthurium andreanum cv. Rubrun plants from callus tissue through organogenesis. Micropropagation of this plant species after seed germination is also described.

\section{MATERIALS AND METHODS}

\section{Plant material}

Explants were obtained from plants of $A$. andreanum cv Rubrun germinated from seeds. The fruits were separated from spadixes and sterilized for $15 \mathrm{~min}$ in $3 \% \mathrm{NaOCl}$ and then rinsed three times with sterile water for $30 \mathrm{~min}$, following the protocol established by Pierik et al. (1974), modified as follows: one hundred seeds were isolated and sterilized for $20 \mathrm{~min}$ in $1 \% \mathrm{NaOCl}$, and afterwards they were washed two times with sterile water for $30 \mathrm{~min}$. Two media were tested for seed germination. They shared a basal composition of Murashige and Skoog, (1962), supplemented with $1.2 \mu \mathrm{M}$ thiamin, $0.6 \mu \mathrm{M}$ myo-inositol, $3 \%$ sucrose and $0.2 \%$ Gelrite, $\mathrm{pH}$ was adjusted to 5.8 before autoclaving. Media differed in concentration of hormones and environmental conditions of culture: a) Fifty seeds were cultivated on a medium without hormones and incubated under continuous fluorescent light $(50 \mu \mathrm{mol} \mathrm{m}$ $\mathrm{s}^{-1}$ ) at $25^{\circ} \mathrm{C}$ and b) Fifty seeds were cultivated on a medium supplemented with $2.2 \mu \mathrm{M} \mathrm{BA}$ and incubated in darkness at $25^{\circ} \mathrm{C}$.

\section{Micropropagation of Anthurium andreanum}

After 4 weeks, we used one of the plants germinated from seeds as source of explants. Four micro-cuttings were inoculated on Murashige and Skoog, (1962) medium supplemented with $4.4 \mu \mathrm{M}$ BA and $0.05 \mu \mathrm{M}$ NAA and incubated under continuous fluorescent light $\left(50 \mathrm{mE} . \mathrm{m}^{-2} . \mathrm{s}^{-}\right.$ ${ }^{1}$ ) at $25^{\circ} \mathrm{C}$. Eight weeks later, 20 micro-cuttings were obtained for micropropagation experiments. These microcuttings were cultured in the conditions described above.

\section{Callus culture}

At the stem base of the 8 weeks-old plants originated from micro-cuttings, a proliferation of callus tissue was observed. Twenty segments of approximately $1 \times 1 \mathrm{~cm}$ of these calli were subcultivated on the same Murashige and Skoog, (1962) basal medium supplemented with $8.9 \mu \mathrm{M}$ $\mathrm{BA}$ and $2.7 \mu \mathrm{M}$ NAA and were incubated under continuous fluorescent light $\left(50 \mu \mathrm{mol} \mathrm{m}^{-2} \mathrm{~s}^{-1}\right)$ at $25^{\circ} \mathrm{C}$.

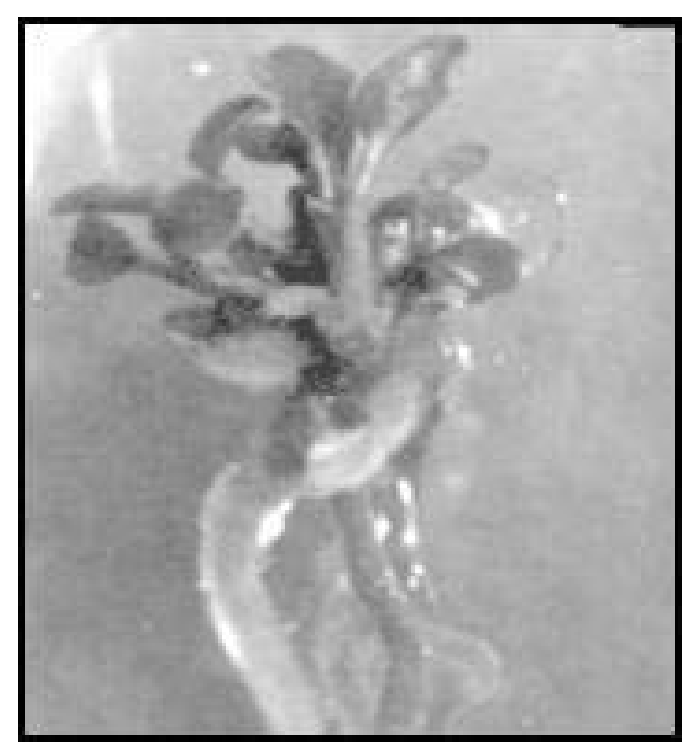

Figure 2. A. andreanum plantlets from germinated seeds under continuous light conditions. 


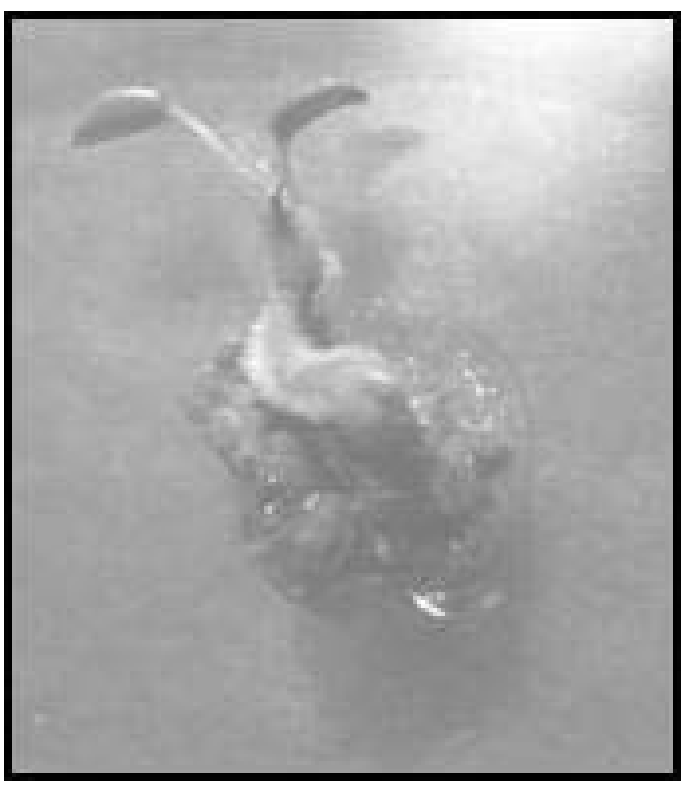

Figure 3. Callus proliferation on $A$. andreanum plantlets from germinated seeds under dark conditions.

\section{Acclimatization}

Plantlets originated from callus tissue were maintained on the same medium during 4 months and then were transferred to Murashige and Skoog, (1962) medium without hormones for three months. Later, these 7 months old plants were removed from the culture tubes. The roots were washed in tap water and the plants were transferred to pots containing a mixture of soil and organic humus $(1: 1)$. The plants were kept on chambers with high relative humidity and low light intensity. One month later, when the

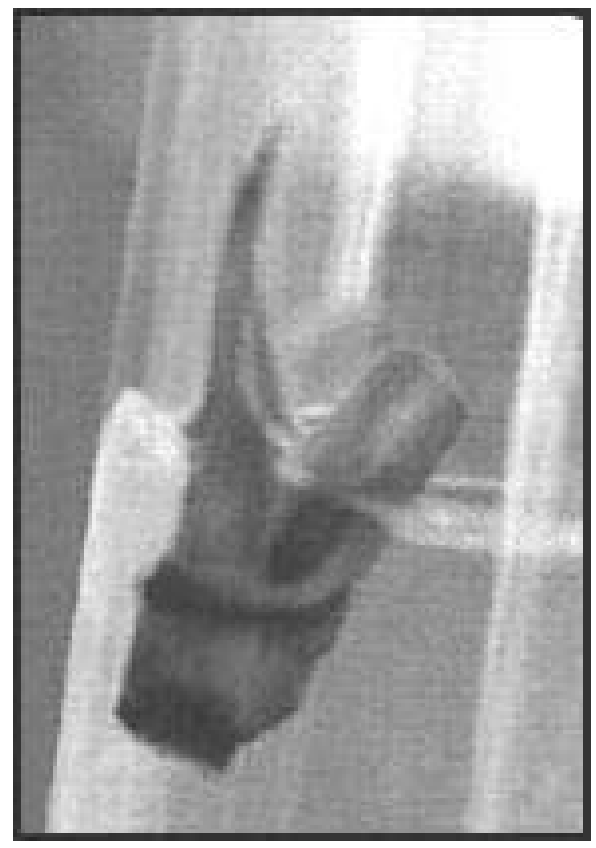

Figure 4. Shoot development from micro-cuttings 2 weeks after induction. plants shown growth, they were transferred to the greenhouse.

\section{Histological analysis}

For the histological observations the tissues were fixed in FAA (40\% formaldehyde, $10 \%$ glacial acetic acid, $50 \%$ ethanol) for at least two days, followed by dehydration in series of tert-butyl-ethanol and ethanol (De García and Martínez, 1995). Then they were embedded in paraplast for sectioning in a rotatory microtome $(10-12 \mathrm{~mm})$ followed by staining with safranine and fast green. The observations and photomicrograph were done with a Wild Heerbrugg optical microscope model M20EB, equipped with a camera.

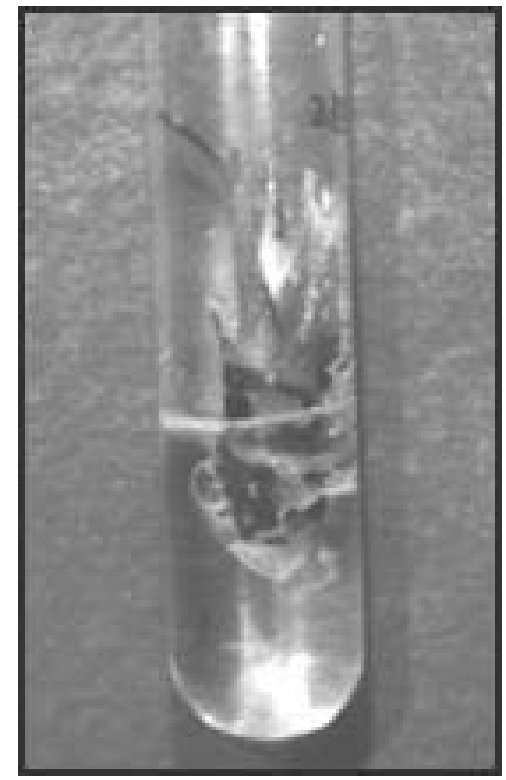

Figure 5. Shoot development from micro-cuttings 6 weeks after induction.

\section{RESULTS}

\section{In vitro seed germination of Anthurium andreanum}

After one week, $74 \%$ of the seeds cultivated under continuous light conditions were germinated in comparison with $30 \%$ of germination showed by seeds cultivated on Murashige and Skoog, (1962) medium with BA incubated in darkness. One week later the radicle emerged and shoot developed under continuous light (Figure 1). On the contrary, germinating seeds cultivated on darkness did not show development of shoots and radicle at this time. The germinated seeds were all transferred to a medium without hormones under light conditions. Two weeks later, the plantlets previously developed under light conditions were $2 \mathrm{~cm}$ high with 3 leaves and showed 2-3 pubescent roots (Figure 2). The plantlets obtained from seeds germinated under dark conditions showed callus proliferation at the stem base (Figure 3), and they were $1 \mathrm{~cm}$ lower than plantlets cultivated under light conditions. 


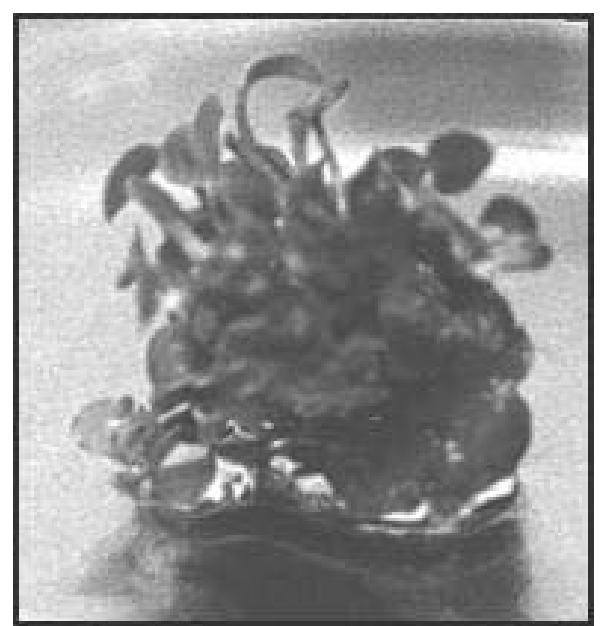

Figure 6. Shoot proliferation from organogenic callus of $A$. andreanum.

\section{Micropropagation of Anthurium andreanum plants from micro - cuttings}

After two weeks, buds from micro-cuttings cultivated on Murashige and Skoog, (1962) medium enlarged $0.5 \mathrm{~cm}$ (Figure 4). Four weeks later an average of 3.6 shoots were produced per explant, these shoots were $1.5 \mathrm{~cm}$ high and showed two to three leaves (Figure 5). We also observed the proliferation of callus tissue at the base of these shoots which produced on average 6.6 small plantlets per $1 \times 1 \mathrm{~cm}$ callus fragment.

\section{Plant regeneration through callus culture}

Callus tissues originated at the stem base of $A$. andreanum plantlets obtained from micro - cuttings culture, were subcultured and 6 weeks later these green and compact calli had increased their size twice. We obtained an average of 43.8 plantlets per callus fragment (Figure 6). Anatomical studies showed that these green calli had organogenic potential (Figure 7) showing numerous shoot primordia.

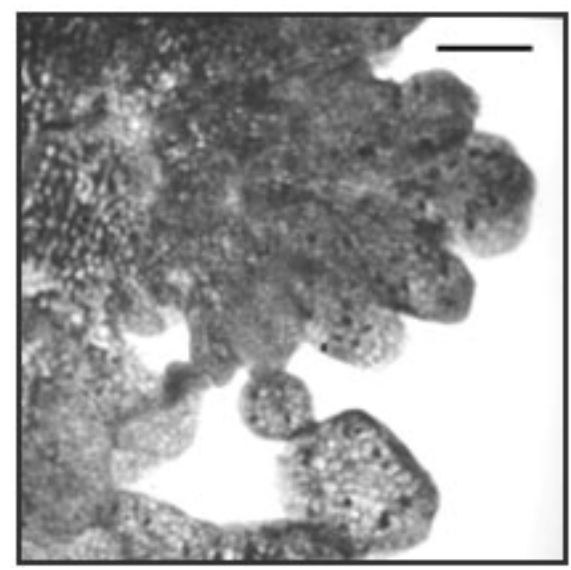

Figure 7. Organogenic callus showing shoot primordia. (Scale bar $=310 \mathrm{~mm}$ ).

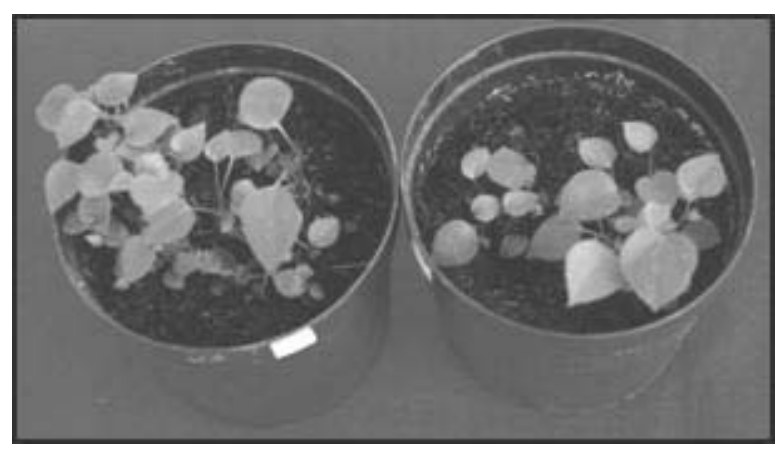

Figure 8. A. andreanum plants under greenhouse conditions.

\section{Acclimatization}

Under the acclimatization conditions used in this work, the success rate was $80 \%$. The acclimatized plants showed the same morphology than the Anthurium andreanum plants used as seeds source (Figure 8).

\section{DISCUSSION}

An efficient regeneration system for $A$. andreanum from micro - cuttings and from callus tissue was achieved in this research. Previous reports have shown that the vegetative propagation of several Anthurium species is a very difficult task (Pierik et al. 1974; Pierik and Steegmans, 1976; Hamidah et al. 1997), moreover, the application of culture techniques, have been also difficult to establish because of the high contamination indexes observed in these culture (Brunner et al. 1995). We showed here that using plants from germinated seeds permitted to eliminate the contamination problems we previously encountered using explants from plants grown in the greenhouse. Our results show that there are high germination percentages of $A$. andreanum seeds, under continuous light conditions. Plantlets issued from seeds and callus formed at the basal zones of the micropropagated plants, allowed to set up alternative regeneration systems for $A$. andreanum. Kuehnle and Sugii (1991) obtained embryogenic callus from plant spadixes and organogenic callus from leaf explants of several Anthurium hybrids. They maintained long-term cultures of callus from Univ. of Hawaii anthurium selections UH965, UH1060 and UH1003 for 12 to 13 months and were still capable of plantlet regeneration. However they do not report the number of regenerated plantlets per callus fragment. Geier (1986) recognized that the easiest way to get organogenic callus is using young leaf explants, but multiplication and rooting of regenerated plants were not so easy. Our results show that callus tissue originated at the base of either regenerated plants or vitroplants obtained from seeds cultivated in dark conditions, has organogenic determination. The sub-culture of these calli on suitable media, generates a higher number of shoots per callus fragment than the number of shoots originated from micro-cuttings culture. The rooting process occurs on Murashige and Skoog, (1962) medium without 
hormones. Plants potted on a mixture of soil and organic humus were successfully acclimated.

\section{REFERENCES}

BRUNNER, I.; ECHEGARAY, A. and RUBLUO, A. Isolation and characterization of bacterial contaminants from Dieffenbachia amoena Bull, Anthurium andreanum Linden and Spathiphyllum sp. shoot cultured in vitro. Scientia Horticulturae, 1995, vol. 62, no. 1-2, p. 103-111.

CHEN, F.C.; KUEHNLE, A.R. and SUGII, N. Anthurium roots for micropropagation and Agrobacterium tumefaciens-mediated gene transfer. Plant Cell Tissue and Organ Culture, 1997, vol. 49, no. 1, p. 71-74.

DE GARCÍA, E. and MARTÍNEZ, S. Somatic embryogenesis in Solanum tuberosum cv Dèsirèe from stem nodal sections. Journal of Plant Physiology, 1995, vol. 145 , no. 4 , p. $526-530$.

DUFOUR, L. and GUERIN, V. Growth, developmental features and flower production of Anthurium andreanum Lind. in tropical conditions. Scientia Horticulturae, 2003, vol. 98 , no. 1, p. 25-35.

GEIER, T. Factors affecting plant regeneration from leaf segments of Anthurium scherzerianum Schott cultured in vitro. Plant Cell Tissue and Organ Culture, 1986, vol. 6, p. 115-125.

HAMIDAH, M.; KARIM, A.G.A. and DEBERGH, P. Somatic embryogenesis and plant regeneration in Anthurium scherzerianum. Plant Cell Tissue and Organ Culture, 1997, vol. 48, p. 189-193.

KUEHNLE, A.R. and SUGII, N. Callus induction and plantlet regeneration in tissue cultures of Hawaiian Anthuriums. HortScience, 1991, vol. 26, no. 7, p. 919-921.

KUNISAKI, J.T. In vitro propagation of Anthurium andreanum Lind. HortScience, 1980, vol. 15, p. 508-509.

MARTIN, K.P.; JOSEPH, D.; MADASSERY, J. and PHILIP, V.J. Direct shoot regeneration from lamina explants of two commercial cut flower cultivars of Anthurium andreanum Hort. In Vitro Cellular and Developmental Biology-Plant, 2003, vol. 39, no. 5, p. 500504.

MURASHIGE, T. and SKOOG, F. A revised medium for rapid growth and bio-assays with tobacco tissue cultures. Physiologia Plantarum, 1962, vol. 15, p. 473-497.

PIERIK, R.L.M. and STEEGMANS, H.H.M. Vegetative propagation of Anthurium scherzerianum Schott through callus cultures. Scientia Horticulturae, 1976, vol. 4, p. 291292.
PIERIK, R.L.M.; STEEGMANS, H.H.M. and VAN DER MEYS, J.A.J. Plantlet formation in callus tissues of Anthurium andreanum Lind. Scientia Horticulturae, 1974, vol. 2, p. 193-198.

TENG, W.L. Regeneration of Anthurium adventitious shoots using liquid or raft culture. Plant Cell Tissue and Organ Culture, 1997, vol. 49, no. 2, p. 153-156. 